\title{
Experimental investigation of stabilization of flowing water temperature with a water-PCM heat exchanger
}

\author{
Pavel Charvat ${ }^{1, \mathrm{a}}$, Josef Stetina ${ }^{1}$, Ondrej Pech ${ }^{1}$, Lubomir Klimes ${ }^{1}$ and Milan Ostry ${ }^{2}$ \\ ${ }^{1}$ Brno University of Technology, Faculty of Mechanical Engineering, Technicka 2896/2, Brno, Czech Republic \\ ${ }^{2}$ Brno University of Technology, Faculty of Civil Engineering, Veveri 95, Brno, 602 00, Czech Republic
}

\begin{abstract}
Experiments have been carried out in order to investigate the stabilization of water temperature with a water-PCM heat exchanger. The water-PCM heat exchanger was of a rather simple design. It was a round tube, through which the water flowed, surrounded with an annular layer of PCM. The heat exchanger was divided into one meter long segments (modules) and the water temperature was monitored at the outlet of each of the segments. A paraffin-based PCM with the melting temperature of $42{ }^{\circ} \mathrm{C}$ was used in the experiments. The experimental set-up consisted of two water reservoirs kept at different temperatures, the water-PCM heat exchanger, $\mathrm{PC}$ controlled valves and a data acquisition system. As the first step a response to a step change in the water temperature at the inlet of the heat exchanger was investigated. Subsequently, a series of experiments with a square wave change of temperature at the inlet of the exchanger were carried out. The square wave temperature profile was achieved by periodic switching between the two water reservoirs. Several amplitudes and periods of temperature square wave were used. The results of experiments show that a water-PCM heat exchanger can effectively be used to stabilize the flowing water temperature when the inlet temperature changes are around the melting range of the PCM.
\end{abstract}

\section{Introduction}

A constant fluid temperature plays an important role in many applications from laboratory experiments to the extracorporeal blood circulation. Some deviations from the desired fluid temperature can occur due to a number of reasons such as imperfect temperature control or fluctuating heat load. The temperature fluctuations can be either stochastic or they can follow a certain pattern (e.g. depending on a dead band of a temperature controller). Thermal storage with both sensible and latent heat storage materials can be employed to attenuate the fluid temperature fluctuations. The behaviour of sensible heat storage used for this purpose is rather independent of the fluid temperature (the same material can be used to attenuate fluid temperature fluctuations at various temperatures). Another advantage of sensible heat storage is rather good thermal conductivity of many sensible heat storage materials, metals in particular. The PCMs provide a high thermal storage capacity in a narrow temperature interval around the phase change temperature [1] and they have already found their application in many areas $[2,3]$.

If a PCM is used for attenuation of fluid temperature fluctuations, it needs to be chosen with regard to the fluid temperature in order to make use of latent heat of phase change (fluid temperature needs to fluctuate over the

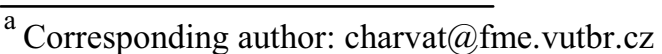

melting range of the material). A schematic representation of the application of heat storage for attenuation of fluid temperature fluctuations is shown in Figure 1.

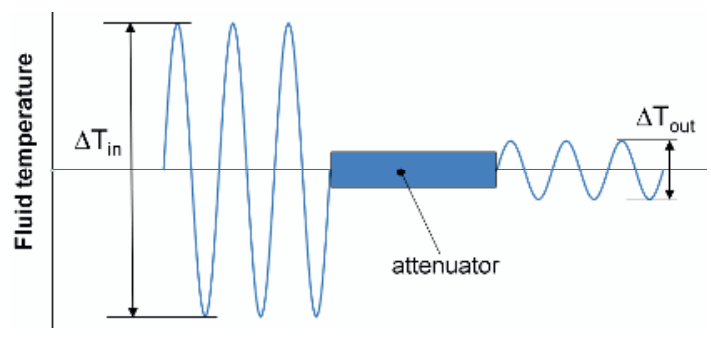

Figure 1. Attenuation of fluid temperature fluctuation.

Some studies into attenuation of temperature gradients or temperature instabilities have been published in the last decade. Lawton et al. [4] reported theoretical analyses and experimental observations of the thermal performance of direct contact packed bed thermal gradient attenuators. The packed bed in this case was a cylindrical canister filled with spheres. The authors presented the attenuator transfer functions for various parameters such as the diameter of the canister, diameter of the spheres, the number of the spheres and the fluid flow rate. The attenuator in the form of a $100 \mathrm{~mm}$ 
diameter plastic canister containing 10,000 steel spheres with the diameter of $6.4 \mathrm{~mm}$ reduced the harmonic variations of water temperature with the peak-to-peak amplitude of $150 \mathrm{mK}$ at the input to variations of just $0.6 \mathrm{mK}$ at the output.

Alawadhi [5] presented a numerical study to evaluate the thermal performance of a fluid temperature regulation unit. The unit was a two-dimensional channel with a phase change material on each side. The author numerically investigated the thermal characteristics of the unit for a step function change and a periodic change of inlet temperature.

Klimes and Charvat [6] presented a heuristic approach used in optimal design of the fluid temperature attenuator with a PCM. They developed a numerical model of the attenuator with the use of the control volume method and the effective heat capacity approach [7]. A possibility to utilize very fast GPGPU computing was investigated as well [8]. Numerical investigation of the influence of the inlet temperature wave forms on the thermal behaviour of the attenuator with sensible and latent heat storage materials is reported in [9].

\section{Problem description}

The idea behind the use of thermal storage for attenuation of fluid temperature fluctuations is the increase of the thermal inertia of the system. The thermal storage material in this case behaves as both the heat sink and the heat source. When the fluid temperature is higher than the temperature of the heat storage material the heat flows from the fluid to the thermal storage material. Similarly, when the fluid temperature is lower than that of the heat storage material the heat flows in opposite direction. Since the overall thermal storage capacity of such thermal mass is limited there are some constraints for attenuation characteristics of this approach in terms of the amplitudes and frequencies of temperature fluctuations. Figure 2 shows one period of the square wave, the sine wave and the triangle wave temperature change with the same amplitude and the same frequency.

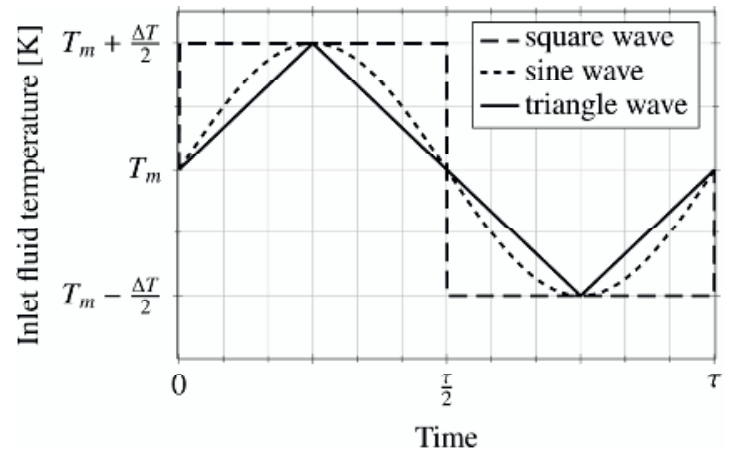

Figure 2. Waveforms

It can be assumed, under quasi-stationary conditions, that when the fluid temperature at the inlet of the attenuator follows one of the waveforms the heat flows from the fluid to the thermal storage material during the first half of the period and it flows from the heat storage material to the fluid during the second half of the period.
The mean value of the heat flux for the whole period (or any number of periods) is zero and the mean fluid temperature at the inlet and the outlet of the attenuator is constant. The amplitude of the fluid temperature fluctuations at the outlet of the attenuator depends on many parameters mostly related to heat transfer - the attenuator in this case is a kind of heat exchanger. If the attenuator only contains sensible heat storage material its attenuation characteristic will be almost independent of the mean fluid temperature at the inlet since the thermophysical properties, such as thermal conductivity and heat capacity, do not significantly change with temperature (in the range of $\pm 30 \mathrm{~K}$ ). The situation changes considerably when latent heat storage is used. The PCMs provide large thermal storage capacity in their melting ranges but their thermal storage capacity is much smaller outside of the melting range.

\section{Experimental set-up}

The investigations presented in this paper were carried out experimentally. The experimental set-up involved two water reservoirs maintained at different temperatures, mixing valve, flow rate control and data acquisition equipment. The schematic of the set-up can be seen in Figure 3. The attenuator (PCM-water heat exchanger) consisted of 6 modules. Each module was $1.1 \mathrm{~m}$ long and it consisted of a cooper tube with the inner diameter of $26 \mathrm{~mm}$. The wall thickness of the tube was $1 \mathrm{~mm}$. There was a plastic tube with the inner diameter of $46 \mathrm{~mm}$ around the copper tube and the space between the tubes was filled with a paraffin based PCM RT42.

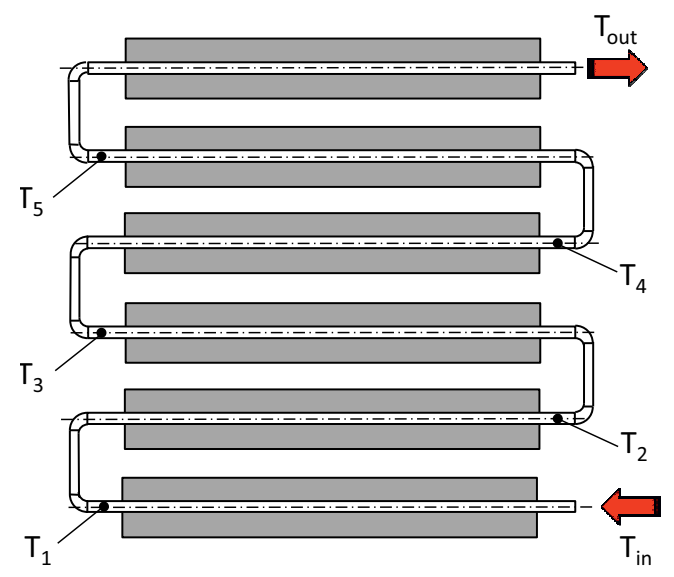

Figure 3. Schematic of the attenuator

Each module accommodated about $0.9 \mathrm{~kg}$ of the PCM. The properties of the PCM are in Table 1. The modules as well as all the piping connecting the modules were thermally insulated to minimize the thermal loss to the surrounding environment.

The RTD temperature sensors (Pt100) were used for water temperature measurements at several points (Figure 3). The type T thermocouples were used for PCM temperature measurements. A magnetic flow meter with the range of 0.4 to 4 liters per minute was used for water flow rate measurements. The experiments were controlled from a PC and the PC was also used for data 
acquisition. All the data were recorded with the frequency of $10 \mathrm{~Hz}$.

Table 1. Properties of RT42

\begin{tabular}{|c|c|}
\hline Melting area & $\begin{array}{c}38-43^{\circ} \mathrm{C} \\
\text { main peak } 41^{\circ} \mathrm{C}\end{array}$ \\
\hline Congealing area & $\begin{array}{c}43-37{ }^{\circ} \mathrm{C} \\
\text { main peak } 42^{\circ} \mathrm{C}\end{array}$ \\
\hline $\begin{array}{c}\text { Heat storage capacity }( \pm 7.5 \%) \\
\text { in the temperature range } 35 \text { to } 50{ }^{\circ} \mathrm{C}\end{array}$ & $174 \mathrm{~kJ}$ \\
\hline Specific heat capacity & $2 \mathrm{~kJ} \mathrm{~kg}^{-1} \mathrm{~K}^{-1}$ \\
\hline Density solid $\left(15^{\circ} \mathrm{C}\right)$ & $880 \mathrm{~kg} \mathrm{~m}^{-3}$ \\
\hline Density liquid $\left(80^{\circ} \mathrm{C}\right)$ & $760 \mathrm{~kg} \mathrm{~m}^{-3}$ \\
\hline Heat conductivity & $0.2 \mathrm{~W} \mathrm{~m}^{-1} \mathrm{~K}^{-1}$ \\
\hline Volume expansion & $12.5 \%$ \\
\hline Maximum operation temperature & $72{ }^{\circ} \mathrm{C}$ \\
\hline
\end{tabular}

\section{Results and discussion}

The first set of experiments focused on the thermal response of the experimental set-up in general and the response of the attenuator (heat exchanger) in particular. It usually took about an hour to reach quasi-stationary conditions (the conditions in which the average temperature did not change over time). This finding was quite important for the experiments.

The response to a step change of the inlet water temperature of $\Delta T=30 \mathrm{~K}$ is shown in Figure 4 . The water flow rate was 3 litres/min $\left(0.18 \mathrm{~m}^{3} \mathrm{hr}^{-1}\right)$. Water from the reservoir with the lower water temperature (in this case $T_{i n}=22.5^{\circ} \mathrm{C}$ ) was supplied to the attenuator until the outlet water temperature was the same as the inlet water temperature (a quasi-stationary state). Then the water supply was switched to the reservoir with the higher water temperature $\left(T_{i n}=52.7^{\circ} \mathrm{C}\right)$. After about an hour when a new quasi-stationary state was reached, water from the cooler reservoir was again supplied to the attenuator. The heat loss of the attenuator increases with water temperature and the outlet water temperature did not reach the inlet water temperature when warm water was supplied to the attenuator.

The second set of experiments focused on the attenuation of the water temperature fluctuations during periodic switching between two water reservoirs (thermal baths). Such periodic switching should theoretically lead to square wave temperature fluctuations at the inlet of the attenuator. The square wave is rather easy to use in numerical simulations [9], but it is less easy to produce during experiments. Due to the inertia of the system and the time necessary for switching the mixing valve (3-way valve) from one position to the other the temperature change at the inlet was not as perfect as the square wave shown in Figure 2. The results are for the water flow rate of $2 \mathrm{l} / \mathrm{min}\left(0.12 \mathrm{~m}^{3} \mathrm{hr}^{-1}\right)$. The shift between the inlet and the outlet temperature waves is caused by the length of the attenuator. At the flow rate of $21 / \mathrm{min}$ it took about 1 minute for the water to flow from the inlet to the outlet of the attenuator. Several frequencies (periods) of the temperature waves were investigated. Since it was necessary to run the experiment for about an hour before reaching the quasi-stationary conditions it was almost impossible to perform all experiments with exactly the same peak-to-peak inlet water temperature amplitudes.

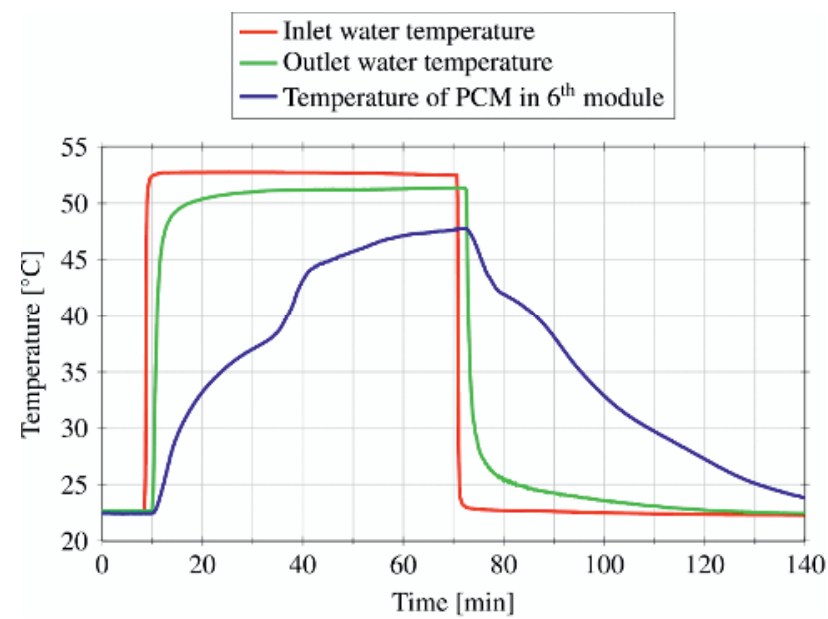

Figure 4. Response to a step change of inlet water temperature

Figure 5 shows the input and output temperature for the wave period of 240 seconds. The peak-to-peak temperature amplitude at the inlet was $21.9 \mathrm{~K}$ and the peak-to-peak temperature amplitude at the outlet was $11.8 \mathrm{~K}$. It means that the outlet temperature amplitude was $54 \%$ of the inlet temperature amplitude.

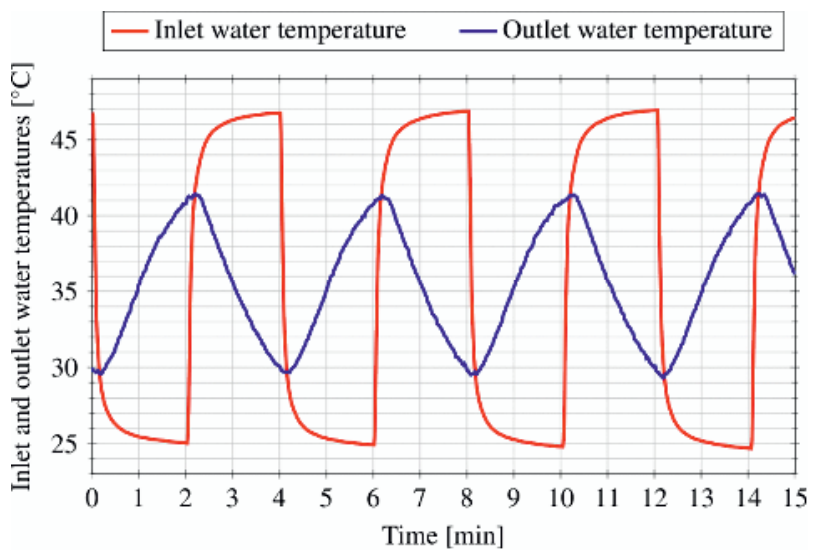

Figure 5. Wave period 240 seconds

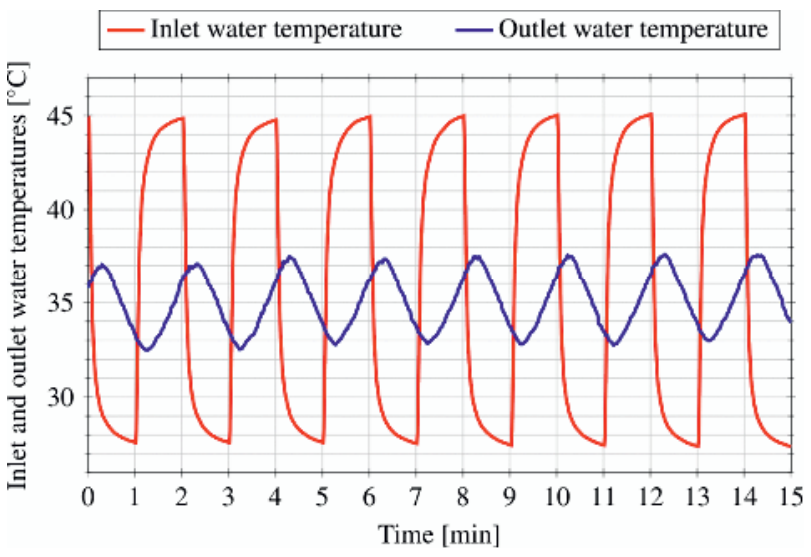

Figure 6. Wave period 120 seconds 
Figure 6 shows the temperature amplitudes for the wave period of 120 second. The inlet water temperature amplitude was $17.4 \mathrm{~K}$ and the outlet amplitude was $4.7 \mathrm{~K}$ ( $27 \%$ of the inlet amplitude). The situation for the $60 \mathrm{~s}$ and $30 \mathrm{~s}$ periods is shown in Figures 7 and 8.

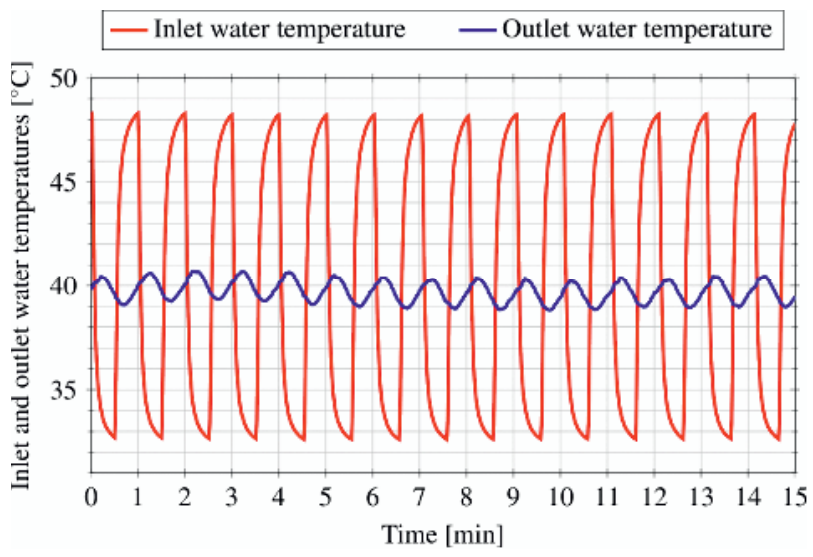

Figure 7. Wave period 60 seconds

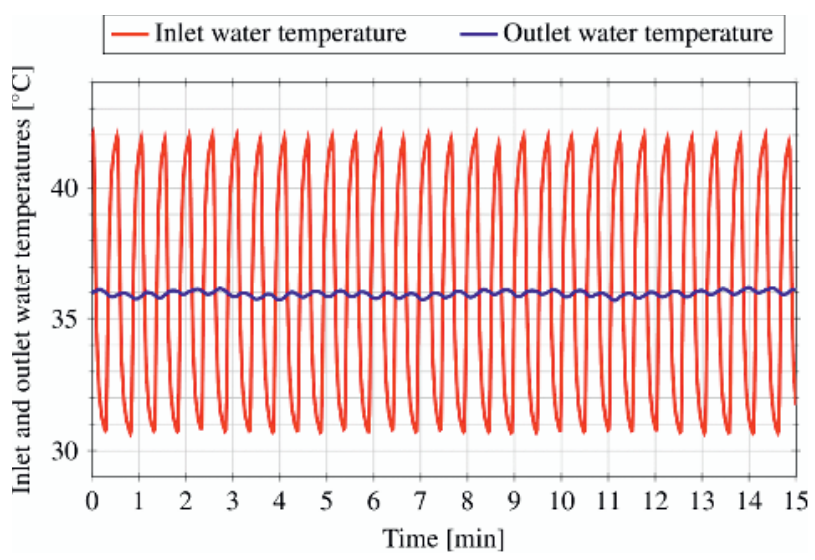

Figure 8. Wave period 30 seconds

The inlet temperature amplitude in case of the 60 second wave period was $15.6 \mathrm{~K}$ and the outlet temperature amplitude was $1.4 \mathrm{~K}$ (about $9 \%$ of the inlet amplitude). The attenuation of the water temperature fluctuations was the strongest in case of the 30 second wave period. The inlet temperature amplitude was $11.2 \mathrm{~K}$ and the outlet amplitude of the water temperature fluctuations was $0.23 \mathrm{~K}(2 \%$ of the inlet temperature amplitude). All the above mentioned amplitudes are the average peak-to-peak amplitudes obtained over the 15 minute intervals shown in the charts.

The improvement of the control of water temperature in the reservoirs is currently in progress in order to perform experiments at exactly the same peak-to-peak amplitudes of inlet water temperature fluctuations. The preparations for the experiments with sine wave temperature fluctuations are also in progress.

\section{Conclusions}

An experimental set-up for investigations of the attenuation of fluid temperature fluctuations with the use of thermal storage in phase change materials was put together and the initial sets of experiments have been carried out. A paraffin-based PCM with the melting range between $37^{\circ} \mathrm{C}$ and $43{ }^{\circ} \mathrm{C}$ was used as the thermal storage material and water was the fluid in all experiments. The experiments focused on the square wave fluctuations of the water temperature achieved by the periodic switching between two water reservoirs maintained at different temperature.

The results show that the wave period has a significant impact on attenuation of water temperature fluctuations. However, such result is not surprising and it is in agreement with expectations. The experiments were performed for waves (temperature fluctuations) with the peak-to-peak amplitudes larger than the melting range of the PCM. More experiments are needed to investigate the influence of latent heat. It can be expected that for the same peak-to-peak amplitude the attenuation of the temperature fluctuations will be stronger when the temperature fluctuations are within the melting range of the PCM - contrary to the fluctuations outside of the melting range where the PCM is in one state (solid or liquid) and its thermal capacity is much smaller.

\section{Acknowledgements}

The authors acknowledge financial support provided by the Czech Science Foundation under contract number P101/11/1047, NETME Centre ED0002/01/01 and from the specific research project for young scientists BUT FSI-J-13-1977. The co-author, the holder of Brno PhD Talent Financial Aid sponsored by Brno City Municipality, also gratefully acknowledges for that financial support.

\section{References}

1. A. Sharma, V. V. Tyagi, C. R. Chen, D. Buddhi, Renewable and Sustainable Energy Reviews, 13, 318-345, (2009).

2. F. Kuznik, D. David, K. Johannes, J.J. Roux, Renewable and Sustainable Energy Reviews, 15, 379-391, (2011).

3. M. Kenisarin, K. Mahkamov, Renewable and Sustainable Energy Reviews, 11, 1913-1965, (2007).

4. K. M. Lawton, S. R. Patterson, R. G. Keanini, Review of Scientific Instruments, 74, 2886-2893.

5. E. M. Alawadhi, Applied Thermal Engineering, 25, 435-449 (2005).

6. L. Klimes, P. Charvat, Proc. of $18^{\text {th }}$ Conference on soft computing MENDEL, 338-343 (2012).

7. L. Klimes, P. Charvat, M. Ostry, Materiali in Tehnologije, 46, 335-338 (2012).

8. L. Klimes, J. Stetina, Proc. of $19^{\text {th }}$ Conference on soft computing MENDEL, 397-402 (2013).

9. P. Charvat, L. Klimes, J. Stetina, M. Ostry, Materiali in Tehnologije, 48 (3), (2014), in print. 